\title{
Encapsulation of paclitaxel in electrosprayed chitosan nanoparticles
}

\author{
Yücel BAŞPINAR 1 * (D), Hasan AKBABA 1 (D), Oğuz BAYRAKTAR 2 (D) \\ 1 Department of Pharmaceutical Biotechnology, Faculty of Pharmacy, Ege University, Bornova 35100 İzmir, Turkey \\ 2 Department of Chemical Engineering, Faculty of Engineering, Ege University, Bornova 35100 İzmir, Turkey \\ * Corresponding author. E-mail: yucel.baspinar@ege.edu.tr (Y.B.); Tel. +90-232-311 2532.
}

Received: 16 April 2019 / Revised: 15 August 2019 / Accepted: 15 August 2019

\begin{abstract}
Paclitaxel is an anti-cancer drug, used to treat ovarian, breast and non-small-cell lung cancer among others. The low aqueous solubility of paclitaxel is a limiting factor for its application. Thus, paclitaxel is solubilized with help of surfactants and co-solvents, approved as Taxol@. Unfortunately, serious side effects like life-threatening hypersensitivity reactions and hemo-toxicity are limiting its use. Due to this, alternative formulations of paclitaxel are required. Nanoparticles represent an important approach to improve the poor solubility of drugs. In that context, electrospray for the preparation of nanoparticles is a promising approach. Due to these facts it was aimed in this study to develop and characterize paclitaxel loaded zein nanoparticles with and without the addition of chitosan. For that purpose the influence of the preparation parameters like the applied voltage and the flow rate on the characteristic properties of the particles were investigated step by step. The nanoparticles were characterized by investigating their particle size, size distribution, zeta potential, shapes and morphologies with help of dynamic light scattering, encapsulation efficiencies and AFM images, respectively. It was succeeded to prepare paclitaxel loaded zein nanoparticles without chitosan at a voltage of $22.5 \mathrm{kV}$ and a flow rate of $0.2 \mathrm{ml} / \mathrm{h}$ having a particle size of $231 \mathrm{~nm}$ and an encapsulation effciency of $89 \%$, while the paclitaxel loaded zein nanoparticles with chitosan had a particle size of 339 $\mathrm{nm}$ and an encapsulation effciency of $94 \%$, prepared with $22.5 \mathrm{kV}$ and a flow rate of $0.3 \mathrm{ml} / \mathrm{h}$.
\end{abstract}

KEYWORDS: Paclitaxel; nanoparticles; electrospray; chitosan; cytotoxicity; lung cancer.

\section{INTRODUCTION}

The diterpenoid ester paclitaxel (PTX) is a first line anti-cancer drug, used for the therapy of ovarian, breast and non-small-cell lung cancer among others [1]. Lung cancer remains $23 \%$ of cancer-related deaths worldwide, more than the sum of breast, colon and prostate cancer [2,3]. Most of the therapeutic approaches like chemotherapy are costly, complex and lacks patient compliance and drug targeting. Current treatment strategies against lung cancer comprise nanoparticles like liposomes and solid lipid nanoparticles among others [4]. In recent years nanoparticulate drug delivery systems have attracted increasing attention, especially regarding anticancer therapy. The anticancer drug PTX was used in various nanoparticulate delivery systems, having advantages compared to the standard therapy, like increasing the aqueous solubility of PTX by conjugated with water-soluble polymers, or encapsulated into lipid-based NPs. Furthermore, NPs are in the nanometer range, enabling the delivery of PTX into the tumor site due to the enhanced permeability and retention effect, can escape the reticuloendothelial system and therefore reduce the undesired effects. One more important advantage is the fact that the pharmacokinetic profiles of the drug from NPs is improved, like increasing the half-life and tumor accumulation of PTX. PTX influences several processes, finally resulting in cell cycle arrest in anaphase stage [5]. Due to its low aqueous solubility, using surfactants and cosolvents can increase the aqueous solubility of PTX as Taxol ${ }^{\circledR}$, which was approved by US FDA in 1992.

Its use is limited by side effects like hypersensitivity reactions and hemo-toxicity [6]. The pharmacokinetic profile of PTX in Taxol ${ }^{\circledR}$ exacerbates the coadministration of other anti-cancer drugs [7]. Further limiting factors for the use of Taxol ${ }^{\circledR}$ are its short biological halflife, poor distribution in plasma, physical instability and incompatibility with infusion sets [8]. Another approved formulation of PTX $\left(\right.$ Abraxane ${ }^{\circledR}$ ) can avoid hypersensitivity reactions [9]. Unfortunately, its elimination, half-life, neutropenia, neuropathy, significant higher cost, only minor improvement in anti-cancer efficacy together with a similar survival rate like Taxol${ }^{\circledR}$ are serious limiting factors [10]. Thus, alternative PTX formulations are required.

How to cite this article: Başpınar Y, Akbaba H, Bayraktar O. Encapsulation of paclitaxel in electrosprayed chitosan nanoparticles. J Res Pharm. 2019; 23(5): 886-896. 
For improving the low solubility of PTX, reducing the side effects and improving anti-cancer efficacy of Taxol$^{\circledast}$ several drug delivery systems have been formulated [11]. Due to their biological inertness and improved stability among others, liposomes are one of the most investigated carrier for PTX [12].

Hydrophilic drugs can be encapsulated in the aqueous core of liposomes and hydrophobic drugs in the lipid bilayer. However, the drug quantity loaded into the bilayer is limited. In addition, loading of high amounts of lipophilic drugs like PTX in bilayer can result in crystallization, which is a serious disadvantage of liposomes [13-16]. Another important approach to improve the poor aqueous solubility is to use nanotechnology and nanoparticles (NPs), having a small size in the nanometer range [17-19].

Several methods has been described for nanotechnology based formulations like, liposomes [20], microemulsions [21], micelles [22], PLGA nanoparticles [23,24], solid lipid nanoparticles [25], lipid nanocapsules [26] and nanoemulsions [27]. In addition, the spray-dried micro- or nanoparticles [28], solvent emulsion-evaporation [29-31], electrohydrodynamic atomization and so-called electrospray [32] were referred. A simple and one-step method for encapsulation of actives is electrospray or electrohydrodynamic atomization [33-35]. Electrospray is generally used for the preparation of polymeric NPs and encapsulation of drugs with poor aqueous solubility, just like PTX. Electrospray is based on the break-up of a liquid into fine droplets in an electric field. A liquid passing through a thin metal tube like a nozzle or needle or capillary with a meniscus at the tip of the tube is electrically stressed due to a potential difference between the tube and the electrode. Electrospray offers advantages like monodispersed particles or controlled particle sizes by adjusting the preparation conditions [36,37], high encapsulation efficiencies [38,39], avoiding separation process to remove the particles from the solvent and conveniently obtaining core-shell structured particles [40]. The complex electrospraying process is affected by many variables such as electrostatic field strength, tube diameter, flow rate and concentration of the compounds. Although electrosprayed particles are in (sub)micron range different strategies to decrease the particle size were used. Nanosized particles were obtained by modifying parameter like applied voltage, feed rate and polymer concentration [41]. Chitosan (Ch) particles with a size of approximately $100 \mathrm{~nm}$ were prepared by reducing polymer concentration and flow rate [42]. It must be pointed out that decreasing the particle size by reducing the concentration of the compounds or flow rate can result in low particle production capacity.

Due to previous experiences of encapsulating lycopene [43] and curcumin [44] with zein, this maize protein was chosen for encapsulation of PTX. Zein contains a group of alcohol soluble but aqueous insoluble proteins [45]. There are many reports about the use of zein as material for encapsulation of several compounds [46-48]. Being biofunctional and non-toxic are important properties for the pharmaceutical industry. Therefore, natural polymers like zein or $\mathrm{Ch}$ are suitable compounds for the preparation of NPs. The cationic polymer Ch can form NPs by different methods like microemulsion and emulsification solvent diffusion among others [49]. Ch exhibits some promising properties like being nontoxic, biodegradable and biocompatible [50]. Due to its positive charge $\mathrm{Ch}$ can interact with negatively-charged sites on a cell surface [51]. These beneficial properties made $\mathrm{Ch}$ to a popular polymer for the development of carrier systems with bioactive compounds as delivery systems for a variety of applications [52]. Due to the fact that the surface of all physiological membranes including the intestine, have a negative surface charge [53], positively charged NPs containing $\mathrm{Ch}$ (ChNPs), proven to enhance the absorption [54], makes them very attractive.

Due to these facts it was aimed in this study to prepare PTX loaded ChNPs having a particle size of maximum $500 \mathrm{~nm}$, a high encapsulation efficiency of $>90 \%$ and an enhanced cytotoxicity on lung cancer cells. For that purpose, PTX was encapsulated using zein in the NPs and additionally $\mathrm{Ch}$. The NPs were prepared using electrospray by varying the applied voltage $(17.5,20$ and $22.5 \mathrm{kV})$ and flow rate $(0.2$ and $0.3 \mathrm{ml} / \mathrm{h})$. The NPs were characterized by investigating their shape, morphologies and particle sizes with help of atomic force microscopy (AFM) and dynamic light scattering (DLS) methods, respectively and encapsulation efficiencies per UPLC.

\section{RESULTS AND DISCUSSION}

\subsection{Characterization of the nanoparticles}

The effect of the flow rate $(0.2$ and $0.3 \mathrm{ml} / \mathrm{h})$ and of the applied voltage $(17.5,20$ and $22.5 \mathrm{kV})$ on the particle size, size distribution, expressed as polydispersity index (PDI) and the zeta potential (ZP) was studied for NPs without the addition of $\mathrm{Ch}$ and for ChNPs. In addition, the prepared NPs were characterized according to the shape of the particles with help of AFM images. The main variables that affect the electrospraying process include the concentration of the polymers zein and $\mathrm{Ch}$ and the preparation conditions (applied voltage and flow rate). Based on our previous studies the zein concentration for the prepared NPs 
was set as $5 \%(\mathrm{w} / \mathrm{w})[39,40]$. Due to low aqueous solubility of $\mathrm{Ch}$, there is a limit for incorporating Ch into the NPs. Therefore, the Ch concentration was kept constant at $0.5 \%(\mathrm{w} / \mathrm{w})$ for the ChNPs.

\subsubsection{Characterization of PTX loaded nanoparticles without chitosan}

The particle size, PDI and ZP results of the NPs without Ch are given in Table 1 . The mean particles size and the PDI values of the PTX containing NPs without Ch decreased from $565 \mathrm{~nm}$ (F1) to $264 \mathrm{~nm}$ (F2) and 231 $\mathrm{nm}(\mathrm{F} 3)$, respectively, and from 0.77 (F1), 0.57 (F2) and 0.46 (F3) with increasing applied voltage from $17.5 \mathrm{kV}$ to $20 \mathrm{kV}$ and $22.5 \mathrm{kV}$, respectively, prepared with a flow rate of $0.2 \mathrm{ml} / \mathrm{h}$. Increasing applied voltage resulted in decreased ZPs from $-2.7 \mathrm{mV}(\mathrm{F} 1)$ to $-10.6 \mathrm{mV}(\mathrm{F} 2)$ and $-21.1 \mathrm{mV}(\mathrm{F} 3)$, respectively. The same tendency of increasing the applied voltage when the flow rate was increased from $0.2 \mathrm{ml} / \mathrm{h}$ to $0.3 \mathrm{ml} / \mathrm{h}$. Increasing the applied voltage resulted in decrease of the mean particles size of the PTX containing NPs from $933 \mathrm{~nm}$ (F4) to $480 \mathrm{~nm}$ (F5) and $253 \mathrm{~nm}$ (F6), respectively. In contrast to that the PDI first increased very slightly from 0.79 (F4) to 0.81 (F5), and decreased then to 0.60 (F6) with increasing the applied voltage from $17.5 \mathrm{kV}$ to $20 \mathrm{kV}$ and $22.5 \mathrm{kV}$, respectively. Regarding The ZPs independent from the suffix, the ZPs increased from -2.8 $\mathrm{mV}$ (F4) to $-3.8 \mathrm{mV}(\mathrm{F} 5)$ and $-8.7 \mathrm{mV}(\mathrm{F} 6)$, respectively, with increasing the applied voltage. Comparing the effect of the flow rate revealed that the NP formulation prepared with $17.5 \mathrm{kV}$ and a flow rate of $0.2 \mathrm{ml} / \mathrm{h}$ had a particle size (565 nm, F1) smaller than the NPs prepared with $0.3 \mathrm{ml} / \mathrm{h}(933 \mathrm{~nm}, \mathrm{~F} 4)$. After increasing the applied voltage to $20 \mathrm{kV}$ similar effect was observed, namely that the particle size of the NPs prepared with $0.2 \mathrm{ml} / \mathrm{h}$ (264 nm, F2) is smaller than the NPs prepared with $0.3 \mathrm{ml} / \mathrm{h}(480 \mathrm{~nm}, \mathrm{~F} 5)$. For the NPs prepared with $22.5 \mathrm{kV}$, the opposite result was obtained, namely smaller NPs for the flow rate of $0.2 \mathrm{ml} / \mathrm{h}(231 \mathrm{~nm}, \mathrm{~F} 3)$, compared to $0.3 \mathrm{ml} / \mathrm{h}$ (253 nm, F6). Regarding the PDIs the same tendency was obtained: 0.77 for the NPs prepared with $0.2 \mathrm{ml} / \mathrm{h}$ and $17.5 \mathrm{kV}$ (F1) and 0.79 for $0.3 \mathrm{ml} / \mathrm{h}$ and $17.5 \mathrm{kV}$ (F4). Increasing the applied voltage to $20 \mathrm{kV}$ resulted in PDIs of $0.57(0.2 \mathrm{ml} / \mathrm{h}$ and $17.5 \mathrm{kV}, \mathrm{F} 2)$ and $0.81(0.3 \mathrm{ml} / \mathrm{h}$ and $17.5 \mathrm{kV}, \mathrm{F} 5)$. Again, after $22.5 \mathrm{kV}$ were applied the PDIs were $0.46(0.2 \mathrm{ml} / \mathrm{h}$ and $17.5 \mathrm{kV}, \mathrm{F} 3)$ and $0.60(0.3 \mathrm{ml} / \mathrm{h}$ and $17.5 \mathrm{kV}$, F6). Comparing the ZPs of the prepared NPs revealed more clear results according the tendency. Increasing the flow rate from $0.2 \mathrm{ml} / \mathrm{h}$ to $0.3 \mathrm{ml} / \mathrm{h}$ resulted in similar ZPs for $17.5 \mathrm{kV}$. While for $20 \mathrm{kV}$ the difference between $0.2 \mathrm{ml} / \mathrm{h}$ to $0.3 \mathrm{ml} / \mathrm{h}$ is more pronounced as $-10.6 \mathrm{mV}$ (F2) and $-3.8 \mathrm{mV}$ (F5). Finally, there is a significant difference between the ZPs of the NPs prepared with $0.2 \mathrm{ml} / \mathrm{h}$ to $0.3 \mathrm{ml} / \mathrm{h}$ for $22.5 \mathrm{kV}$ as $-21.1 \mathrm{mV}$ and $-8.7 \mathrm{mV}$. For the electrospray process both, sizes of the NPs and their morphologies may vary with changing flow rates. Usually, sizes of the NPs increase with increasing flow rates. Effect of the applied voltage on the size and morphology of the NPs is much more significant with that of the flow rate. The effect of the applied voltage on the particle size and PDI can be explained with the jet break-up mechanism [46-50]. The applied voltage affects the jet break-up mechanism and depends on the stress ratio at the jet surface, expressed as the ratio of the normal electric stress to the surface tension stress [55]. The higher the applied voltage the smaller are the prepared NPs, with a narrow PDI, expressed as low value. Axisymmetric instabilities lead to a break up at a low stress ratio value, resulting in monodispersed droplets and the fact that the number of secondary droplets is lower than the number of primary droplets. After reaching a stress ratio threshold value, the jet begins to whip and lateral instabilities contribute to the break-up of the jet, resulting in a rise in the number of secondary droplets and satellites [46-50], as in the case of the present work when the voltage was increased from 17.5, 20 and $22.5 \mathrm{kV}$, respectively.

To sum up, combining the particle size, PDI, ZP results with the AFM images revealed that the best PTX loaded NP formulation without $\mathrm{Ch}$ is the formulation $\mathrm{F} 3$, prepared with an applied voltage of $22.5 \mathrm{kV}$ and a flow rate of $0.2 \mathrm{ml} / \mathrm{h}$.

Table 1. The particle size, size distribution (PDI) and zeta potential results of the nanoparticles without chitosan.

\begin{tabular}{lcccccc}
\hline & F1 & F2 & F3 & F4 & F5 & F6 \\
\hline PCS \pm SD [nm] & $565 \pm 147$ & $264 \pm 80$ & $231 \pm 73$ & $933 \pm 641$ & $480 \pm 355$ & $253 \pm 103$ \\
PDI \pm SD & $0.77 \pm 0.21$ & $0.57 \pm 0.38$ & $0.46 \pm 0.13$ & $0.79 \pm 0.26$ & $0.81 \pm 0.32$ & $0.60 \pm 0.43$ \\
$\mathbf{Z P} \pm$ SD [mV] & $-2,7 \pm 0.8$ & $-10,6 \pm 2.4$ & $-21,1 \pm 3.7$ & $-2,8 \pm 0.4$ & $-3,8 \pm 2.1$ & $-8,7 \pm 1.9$ \\
\hline
\end{tabular}

\subsubsection{Characterization of PTX loaded nanoparticles with chitosan}

Table 2 shows the particle size, PDI and ZP results of ChNPs. The mean particle size of the PTX containing ChNPs decreased from $532 \mathrm{~nm}$ (F7) to $359 \mathrm{~nm}$ (F8) and $339 \mathrm{~nm}$ (F9), respectively, with increasing 
applied voltage from $17.5 \mathrm{kV}$ to $20 \mathrm{kV}$ and $22.5 \mathrm{kV}$, respectively, prepared with a flow rate of $0.2 \mathrm{ml} / \mathrm{h}$. The same decreasing effect as 0.94 (F7), 0.88 (F8) and 0.55 (F9) was observed for the PDIs and the ZPs as - $11.6 \mathrm{mV}$ (F7) to $-9.8 \mathrm{mV}$ (F8) and $-3.5 \mathrm{mV}$ (F9), respectively, with increasing applied voltage. In order to investigate the effect of the flow rate on the particle size, PDI and ZPs, it was increased from $0.2 \mathrm{ml} / \mathrm{h}$ to $0.3 \mathrm{ml} / \mathrm{h}$. After increasing the flow rate to $0.3 \mathrm{ml} / \mathrm{h}$, the mean particles size of the PTX containing ChNPs decreased from 531 $\mathrm{nm}$ to $383 \mathrm{~nm}$ and $363 \mathrm{~nm}$, respectively, and the PDI values decreased from 0.76 , to 0.65 and to 0.40 , respectively, with increasing applied voltage. Compared to the ChNPs prepared with a flow rate of $0.2 \mathrm{ml} / \mathrm{h}$, the ZPs increased from $-14.2 \mathrm{mV}$ to $-21.1 \mathrm{mV}$ and $-21.9 \mathrm{mV}$, respectively, with increasing applied voltage. Comparing the effect of the flow rate revealed that there is no difference according the particle size between the ChNPs prepared with a flow rate of $0.2 \mathrm{ml} / \mathrm{h}$ and $0.3 \mathrm{ml} / \mathrm{h}$ (Table 2). Regarding the PDIs, increasing the flow rate resulted in a decrease from 0.94 to 0.76 for $17.5 \mathrm{kV}$, from 0.88 to 0.65 for $20 \mathrm{kV}$ and from 0.55 to 0.40 for $22.5 \mathrm{kV}$. Increasing the flow rate from $0.2 \mathrm{ml} / \mathrm{h}$ to $0.3 \mathrm{ml} / \mathrm{h}$ resulted in similar ZPs for $17.5 \mathrm{kV}(-11.6 \mathrm{mV}$ vs. $-14.2 \mathrm{mV}$ ), while for $20 \mathrm{kV}$ the difference between $0.2 \mathrm{ml} / \mathrm{h}$ to $0.3 \mathrm{ml} / \mathrm{h}$ is more pronounced as $-9.8 \mathrm{mV}$ and $-21.1 \mathrm{mV}$. Finally, the biggest difference was obtained for the applied voltage of $22.5 \mathrm{kV}$ as $-3.5 \mathrm{mV}$ and -21.9 $\mathrm{mV}$. Thus, the formulation F12 has more appropriate particle properties.

Table 2. The particle size, size distribution (PDI) and zeta potential results of the nanoparticles with chitosan.

\begin{tabular}{lcccccc}
\hline & F7 & F8 & F9 & F10 & F11 & F12 \\
\hline PCS \pm SD [nm] & $532 \pm 24$ & $359 \pm 115$ & $339 \pm 43$ & $531 \pm 265$ & $383 \pm 102$ & $363 \pm 56$ \\
PDI \pm SD & $0.94 \pm 0.10$ & $0.88 \pm 0.13$ & $0.55 \pm 0.16$ & $0.76 \pm 0.21$ & $0.65 \pm 0.34$ & $0.40 \pm 0.26$ \\
ZP \pm SD [mV] & $-11.6 \pm 1.5$ & $-9.8 \pm 0.1$ & $-3.5 \pm 0.3$ & $-14.2 \pm 1.2$ & $-21.1 \pm 0.5$ & $-21.9 \pm 1.2$ \\
\hline
\end{tabular}

\subsection{Morphological characterization of the nanoparticles}

The NPs without Ch (F1) and ChNPs (F7), prepared with a voltage of $17.5 \mathrm{kV}$ and a flow rate of 0.2 $\mathrm{ml} / \mathrm{h}$ are not really spherical, suggesting that $17.5 \mathrm{kV}$ is not sufficient to prepare compact NPs, with and without $\mathrm{Ch}$. Increasing the applied voltage to $20 \mathrm{kV}$ resulted in more compact and spherical NPs. Further increase of the applied voltage to $22.5 \mathrm{kV}$ lead to NPs with round shape, a compact structure and a more homogenous distribution, for $0.2 \mathrm{ml}$ and $0.3 \mathrm{ml} / \mathrm{h}$, and for ChNPs and NPs without $\mathrm{Ch}$.

At all the applied voltages of 17.5, 20 and $22.5 \mathrm{kV}$, respectively, the NPs without Ch (Figure 1) showed similar morphologies to those of the ChNPs (Figure 2), investigated with help of AFM images. However, adding $\mathrm{Ch}$ to the NPs seems not to have affected the electrospray process according to the morphology of the NPs. After investigating the AFM images of the ChNPs (F7-F12) and NPs without Ch (F1-F6), it was concluded that the NP formulation without Ch F3 and ChNP formulation F12 revealed particles with a round shape, a compact structure and a more homogenous distribution. The rest of the formulations had some disadvantages like a not satisfying shape of the particles, or too big particles with an inappropriate distribution. It can be seen that these formulations, F3 and F12, have a homogenous particle size distribution, supported with the results of the particle size characterization (Table 1, Table 2).

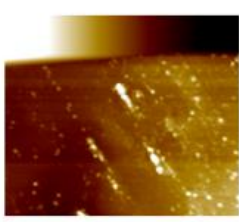

F1

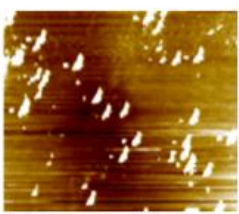

F4

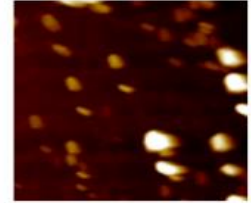

F2

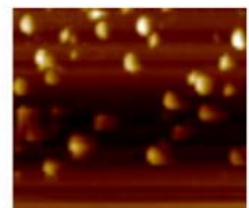

F5

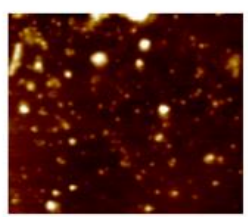

F3

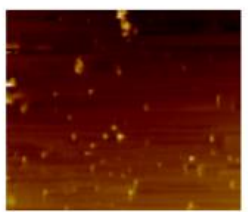

Figure 1. AFM pictures of the paclitaxel nanoparticles without chitosan. 
To sum up, for obtaining compact and spherical ChNPs and NPs without $\mathrm{Ch}$ and a mean particle size of less than $500 \mathrm{~nm}$ by using electrospray, $4.5 \%$ or $5 \%$ zein, respectively, $22.5 \mathrm{kV}$ applied voltage and a flow rate of 0.2 and $0.3 \mathrm{ml} / \mathrm{h}$, respectively, were necessary.

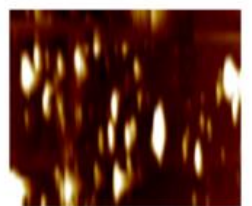

F7

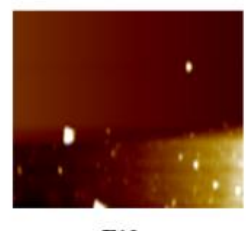

F10

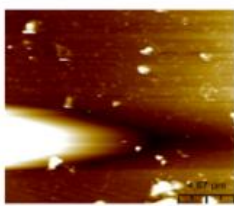

F8

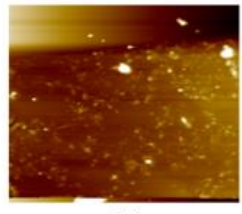

F11

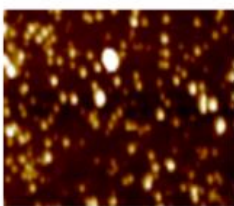

F9

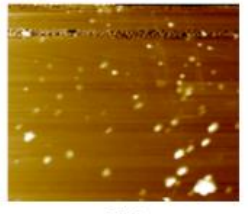

F12

Figure 2. AFM pictures of the paclitaxel nanoparticles with chitosan.

\subsection{The physicochemical stability of the nanoparticles}

The physicochemical stability of the NPs was determined by measuring the particle size, PDI, ZP and drug content of PTX in the NPs without $C h$ and ChNPs after storage of 1 and 3 months at $25 \pm 1^{\circ} \mathrm{C}$, respectively without any significant changes in the particle size and with concentrations of at least $90 \%$ (Table 3 ). However, after storage of 1 and 3 months, respectively the PDI of the NPs without Ch increased from 0.46 (day 0 ) to 0.57 (after 1 month) and 0.60 (3 months), while the ZP decreased from $-21.1 \mathrm{mV}$ to -19.9 (after 1 month) and -14.2 (3 months). For the ChNPs, the PDI increased from 0.40 (day 0) to 0.55 (after 1 month) and 0.65 (3 months), while the ZP decreased from $-21.9 \mathrm{mV}$ to -10.6 (after $1 \mathrm{month}$ ) and -8.7 (3 months). The fact that the negative zeta potential of the nanoparticles with chitosan is decreasing (tendency to positive zeta potential) after storage of three months is showing the increasing loading activity of chitosan, which is a polycationic polymer.

Table 3. The physicochemical stability study results of the nanoparticles without chitosan (F3) and with chitosan (F12) after storage of 3 months at $25 \pm 1^{\circ} \mathrm{C}$.

\begin{tabular}{lcccccc}
\hline & \multicolumn{3}{c}{ Nanoparticles without chitosan (F3) } & \multicolumn{3}{c}{ Nanoparticles with chitosan (F12) } \\
\cline { 2 - 7 } & d0 & 1 month & 3 months & d0 & 1 month & 3 months \\
\hline PTX concentration [\%] & 98 & 96 & 95 & 98 & 96 & 95 \\
PCS \pm SD [nm] & $231 \pm 73$ & $253 \pm 103$ & $264 \pm 80$ & $363 \pm 56$ & $359 \pm 115$ & $383 \pm 102$ \\
PDI \pm SD & $0.46 \pm 0.13$ & $0.57 \pm 0.38$ & $0.60 \pm 0.43$ & $0.40 \pm 0.26$ & $0.55 \pm 0.16$ & $0.65 \pm 0.34$ \\
ZP \pm SD [mV] & $-21,1 \pm 3.7$ & $-19.9 \pm 0.5$ & $-14.2 \pm 1.2$ & $-21.9 \pm 1.2$ & $-10,6 \pm 2.4$ & $-8,7 \pm 1.9$ \\
\hline ad0= day of production & & & & & &
\end{tabular}

\subsection{Cytotoxicity of PTX loaded nanoparticles}

The cytotoxicity results revealed that increasing the PTX concentration from 2.5 to 5, 10, 25 and $50 \mathrm{nM}$, respectively, decreased the viability of A549 lung cancer cells (Figure 3). Using a concentration of $2.5 \mathrm{nM}$ showed no significant difference in viability between the ChNPs (F12) and NPs without Ch (F3). The application of $5 \mathrm{nM}$ resulted in decrease of the viabilities to approximately $90 \%$ (NPs without $\mathrm{Ch}$ ) and 70\% (ChNPs), respectively. Thus, $5 \mathrm{nM}$ is the lowest concentration revealing a significant difference of the viability between the NPs without $\mathrm{Ch}$ and ChNPs. Up to a concentration of $10 \mathrm{nM}$ the viability for the ChNPs is lower that for NPs without Ch. For higher concentrations of $25 \mathrm{nM}$ and $50 \mathrm{nM}$ the viability for the NPs without Ch further decrease, while the viability for the ChNPs did not significantly changed. After application of the highest concentration of $50 \mathrm{nM}$ the viabilities were decreased to $15 \%$ (NPs without $\mathrm{Ch}$ ) and 20\% (ChNPs), respectively. At least a concentration of $10 \mathrm{nM}$ was necessary to kill more than $50 \%$ of 549 lung cancer cells, for both NPs without $\mathrm{Ch}$ and ChNPs. 
This decrease of the viability by increasing the PTX concentration can be explained by the fact that a concentration of $10 \mathrm{nM}$ is necessary to kill the majority of the lung cancer cells.

The findings of this study support the aimed enhanced cytotoxicity of ChNPs and clearly indicate the potential for the treatment of lung cancer with the prepared NPs.

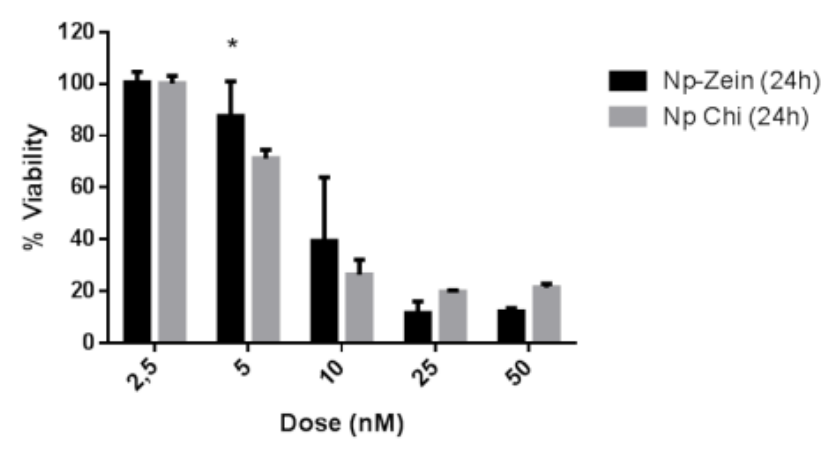

Figure 3. Cytotoxicity results of nanoparticles with and without chitosan.

\subsection{Encapsulation efficiency of PTX loaded nanoparticles}

The encapsulation efficiency (EE) of PTX ranged from 80 to $89 \%$ for the PTX loaded NPs without Ch (Table 1), where by the highest EE of $89 \%$ was obtained with $\mathrm{F} 3$ at a applied voltage of $22.5 \mathrm{kV}$ and a flow rate of $0.2 \mathrm{ml} / \mathrm{h}$. The encapsulation efficiency (EE) of PTX ranged from 81 to $94 \%$ for the PTX loaded ChNPs (Table 2), where by the highest EE of $94 \%$ was obtained with F12 at a applied voltage of $22.5 \mathrm{kV}$ and a flow rate of 0.3 $\mathrm{ml} / \mathrm{h}$.

Increasing the applied voltage from 17.5 to 20 and $22.5 \mathrm{kV}$, at a conctant flow rate of $0.2 \mathrm{ml} / \mathrm{h}$, resulted in increase of the EE from 80 to 81 and $89 \%$, respectively, for the NPs without Ch. Similar tendency was observed for the flow rate of $0.3 \mathrm{ml} / \mathrm{h}$, where the EE increased from 81 to 83 and $86 \%$, respectively. Comparing the EE of the NPs with different flow rates, but a constant applied voltage showed that a significant difference was only observed between F3 (89\%) and F6 (86\%).

Increasing the applied voltage from 17.5 to 20 and $22.5 \mathrm{kV}$, at a conctant flow rate of $0.2 \mathrm{ml} / \mathrm{h}$, resulted in increase of the EE from 81 to 84 and 90\%, respectively, for the ChNPs. Similar tendency was observed for the flow rate of $0.3 \mathrm{ml} / \mathrm{h}$, where the EE increased from 90 to 92 and $94 \%$, respectively. Comparing the EE of the ChNPs with different flow rates, but constant applied voltages showed significant differences for all formulations. This means that the effect of the flow rate and of the applied voltages of the EE is more pronounced for the ChNPs compared to the NPs without Ch.

Similar, high encapsulation efficiencies were achieved by electrospraying, ranging from $80 \%$ to $96 \%$ by other authors [56-58]. Hydrophilic bovine serum albumin (BSA) was encapsulated in the hydrophobic polymers poly(lactic-co-glycolic acid) (PLGA) and poly-caprolactone (PCL), resulting in that the EE mainly depends on the polymer, protein, and organic solvent interactions.

\section{CONCLUSION}

For obtaining NPs without $\mathrm{Ch}$ and ChNPs, prepared with electrospray process, the influence of the applied voltage and the flow rate were investigated as they are important parameter.

The NPs without $\mathrm{Ch}$ and ChNPs were prepared by increasing the applied voltage from $17.5 \mathrm{kV}$ to 20 $\mathrm{kV}$ and $22.5 \mathrm{kV}$, respectively, followed by increasing the flow rate from $0.2 \mathrm{ml} / \mathrm{h}$ to $0.3 \mathrm{ml} / \mathrm{h}$. Combining the particle size, PDI, ZP results with the AFM images and EE results revealed that for preparing suitable NPs without Ch and ChNPs an applied voltage of $22.5 \mathrm{kV}$ and a flow rate of $0.2 \mathrm{ml} / \mathrm{h}$ were needed (F3 and F12). Both NP formulations (F3 and F12) had high EEs of $89 \%$ and $94 \%$, respectively and a satisfying PTX drug content of $95 \%$ after 3 months.

The cytotoxicity results revealed that a PTX concentration of $10 \mathrm{nM}$ were sufficient to decrease the viability of lung cancer cells to 35\% (NPs without $\mathrm{Ch}$ ) and 25\% (ChNPs), respectively.

It was succeed to prepare PTX NPs without Ch and ChNPs having mean particle sizes of $231 \mathrm{~nm}$ and $339 \mathrm{~nm}$, respectively. 


\section{MATERIALS AND METHODS}

\subsection{Materials}

PTX (Figure 4) was supplied from Alfa Aesar, USA, medium molecular weight Ch and zein were purchased from Sigma-Aldrich (Sigma, St. Louis, MO, USA).

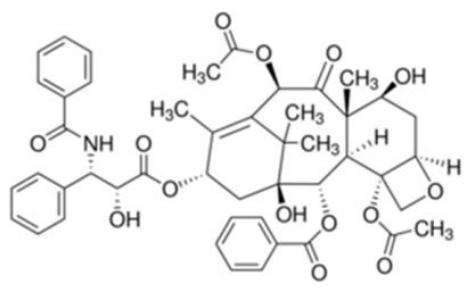

Figure 4. The chemical structure of paclitaxel.

\subsection{Preparation of the PTX loaded nanroparticles by electrospray}

All NPs were prepared by electrospraying process using an apparatus (IMKASAN Basic System Electrospray/coating, Manisa, Turkey) (Figure 5). For the development of the NPs without Ch (Table 1) and ChNPs (Table 2) the formulation parameter and the preparation parameters like the applied voltage $(17.5,20$ and $22.5 \mathrm{kV})$ and the flow rate $(0.2$ and $0.3 \mathrm{ml} / \mathrm{h})$ were investigated.

Due to that fact for preparing NPs with electrospray process, the applied voltage is a key parameter, the voltage was increased from 17.5 to 20 and $22.5 \mathrm{kV}$, respectively. In addition, the flow rate was also increased from $0.2 \mathrm{ml} / \mathrm{h}$ to $0.3 \mathrm{ml} / \mathrm{h}$, respectively and the resulted NPs were characterized according to their particle size and shape with help of DLS and AFM images, respectively.

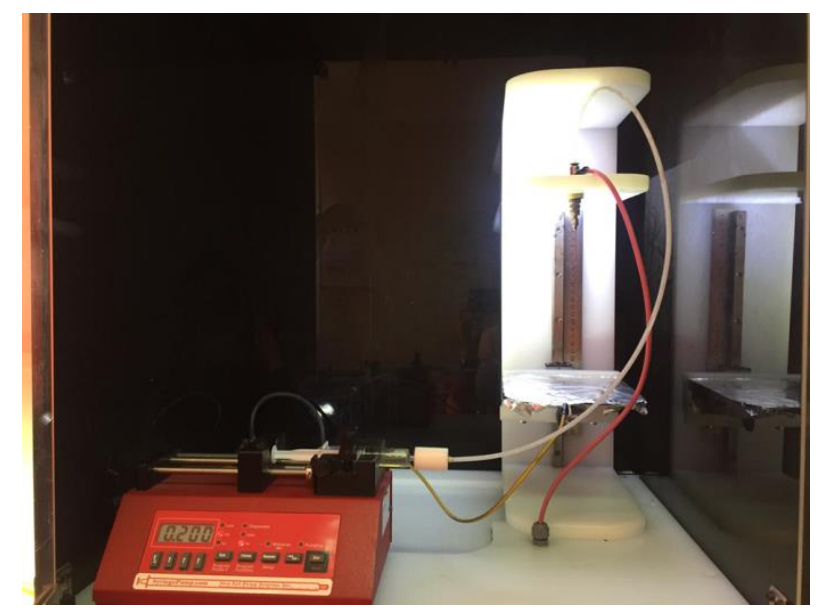

Figure 5. Photograph of the used electrospray apparatus.

\subsubsection{Preparation of PTX loaded nanoparticles without chitosan}

For preparing the PTX loaded NPs first 1\% PTX $(\mathrm{w} / \mathrm{v})$, then $5 \%$ zein $(\mathrm{w} / \mathrm{v})$ was dissolved in $70 \%$ ethanol:water (v/v) solution and stirred at room temperature until they were completely dissolved (Table 4). The NPs were prepared by electrospray using a constant nozzle diameter of $0.6 \mathrm{~mm}$ and a constant zein concentration of $5 \%$, but by varying the flow rate of 0.2 and $0.3 \mathrm{ml} / \mathrm{h}$ and the voltage of $17.5,20$ and $22.5 \mathrm{kV}$. For feeding the solution to the syringe needle an injection pump (New Era, Model NE-1000, Programmable Single Syringe Pump, USA) was used. At a distance of $10 \mathrm{~cm}$ away from the needle tip an aluminum foil covered collector plate was fixed and connected to the counter electrode of the power supply. The solution was fed to process with a plastic syringe and the flow rate of the solution was controlled with syringe pump.

\subsubsection{Preparation of PTX loaded nanoparticles with chitosan}

Due to the fact that medium molecular weight $\mathrm{Ch}$ has not a good aqueous solubility, a $1 \%$ (v/v) acetic acid solution was used to dissolve $0.5 \%(\mathrm{w} / \mathrm{v})$ Ch. For preparing the PTX loaded ChNPs first 1\% PTX (w/v), 
then $0.5 \% \mathrm{Ch}$ and finally $4.5 \%$ zein $(\mathrm{w} / \mathrm{v})$ was dissolved in $70 \%$ ethanol:water $(\mathrm{v} / \mathrm{v})$ solution and stirred at room temperature until they were completely dissolved (Table 4). The NPs were prepared by electrospray using a constant nozzle diameter of $0.6 \mathrm{~mm}$, but by varying the flow rate of 0.2 and $0.3 \mathrm{ml} / \mathrm{h}$ and the voltage of 17.5, 20 and $22.5 \mathrm{kV}$. For feeding the solution to the syringe needle an injection pump (New Era, Model NE1000, Programmable Single Syringe Pump, USA) was used. At a distance of $10 \mathrm{~cm}$ away from the needle tip an aluminum foil covered collector plate was fixed and connected to the counter electrode of the power supply. The solution was fed to process with a plastic syringe and for controlling the flow rate of the solution a syringe pump was used.

Table 4. Formulations of the paclitaxel nanoparticles with (ChNPs) and without (NPs) chitosan.

\begin{tabular}{lcc}
\hline & $\begin{array}{c}\text { NPs } \\
\text { \% (w/v) }\end{array}$ & $\begin{array}{c}\text { ChNPs } \\
\text { \% (w/v) }\end{array}$ \\
\hline PTX & 1 & 1 \\
Zein & 5 & 4.5 \\
Chitosan & - & 0.5 \\
Ethanol/water (70:30) & ad 100 & ad 100 \\
\hline
\end{tabular}

\subsection{Characterization of the nanoparticles}

\subsubsection{Particle size measurement with dynamic light scattering}

A Zetasizer Nanoseries (Malvern Instruments, Malvern, UK) was used for measuring the mean particle size of the PTX loaded NPs per photon correlation spectroscopy (PCS) with dynamic light scattering (DLS).

\subsubsection{Morphological characterization of the nanoparticles}

The morphology of PTX loaded NPs without Ch and ChNPs were measured using atomic force microscope (AFM), Nanomagnetics Instruments ezAFM, Turkey; using a tapping mode at 40×40×4 $\mu \mathrm{m}$.

\subsection{Analyses of paclitaxel concentration with UPLC}

The chemical stability of PTX in the NPs was determined by analysing the drug content of PTX per reversed phase UPLC (Thermo Scientific Ultimate 3000) equipped with a pump and an ultraviolet-visible spectroscopy detector at $227 \mathrm{~nm}$ at a column temperature of $25{ }^{\circ} \mathrm{C}$. The mobile phase consisted of acetonitril:water (80:20). The flow rate was set at $0.8 \mathrm{~mL} /$ minute. Hypersil ODS (Thermo Scientific $5 \mu \mathrm{m}, 4.0 \mathrm{x}$ $125 \mathrm{~mm}$ ) column was used, and the injection volume was $5 \mu \mathrm{L}$. UPLC assay was performed at a PTX concentration range 4-6-8-10-12 $\mu \mathrm{g} / \mathrm{ml}$, respectively with $\mathrm{R}^{2}=0.9988$. This method was modified after [59].

\subsection{Cytoxicity of PTX loaded nanoparticles}

The cytotoxicity of the PTX loaded NPs was determined by XTT cell proliferation assay using the nonsmall-cell lung cancer cell line A549. The A549 cells were cultured in Dulbecco's Modified Eagle's Medium (DMEM) supplemented with $10 \%$ heat-inactivated fetal bovine serum (FBS), penicillin $(100 \mathrm{U} / \mathrm{mL})$, streptomycin $(100 \mu \mathrm{g} / \mathrm{mL})$ and $2 \mathrm{mM} \mathrm{L}$-glutamine in a $37^{\circ} \mathrm{C}$ incubator under $5 \% \mathrm{CO}_{2}$ atmosphere. Prior to treatment, cells were trypsinized and seeded in a final volume of $100 \mu \mathrm{l}\left(5 \times 10^{4} \mathrm{cells} / \mathrm{ml}\right)$ into each well of 96well plates, and incubated for $24 \mathrm{~h}$. At the day of treatment the medium was aspirated, cells were washed with PBS and $50 \mu \mathrm{l}$ of fresh medium was added to each well. Treatment formulations were diluted in the growth medium and added as $50 \mu \mathrm{l}$ portions to the corresponding wells (final volume $100 \mu \mathrm{l}$ ). The viability (\%) of the cells was investigated with increasing the concentration of PTX loaded NPs from 5 to $100 \mu \mathrm{g} / \mathrm{ml}$. Cells were incubated for $24 \mathrm{~h}$ in a $37^{\circ} \mathrm{C}$ incubator under $5 \% \mathrm{CO}_{2}$ in the presence of the formulations. After the incubation the medium was aspirated, cells were washed with PBS and $50 \mu \mathrm{l}$ of fresh medium was added to each well. Subsequently $50 \mu \mathrm{l}$ of XTT reagent prepared as per manufacturers instructions was added and incubated for $2 \mathrm{~h}$ at $37^{\circ} \mathrm{C}$. The specific absorbance of formed orange-colored formazan compound was measured by using an automatic microplate reader (Varioskan Flash microplate reader, Thermo Fisher Scientific, USA) at $450 \mathrm{~nm}$ and 600nm [60]. All experiments were performed in triplicate.

\subsection{Encapsulation efficiency of PTX loaded nanoparticles}

The amount of PTX loaded in the NPs was measured by extracting the NPs in acetone for 3 minutes and centrifugating this mixture at $15000 \mathrm{rpm}$ for 30 minutes using a Hettich Micro 200R centrifuge [61]. The reason 
for the use of acetone for the determination of the EE for PTX was the fact that zein and chitosan are not soluble in acetone, while PTX is soluble. Thus, free (not encapsulated) PTX is located in the upper phase and can be determined with UPLC. Then the upper phase was taken and the concentration of PTX was measured with UPLC. The concentration of PTX in the samples was calculated from the previously prepared standard calibration curve for PTX in mobile phase. The encapsulation efficiency of PTX was calculated as the mass ratio between PTX, determined in the NPs and that used in the preparation of the NPs according to the following equation:

Encapsulation efficiency $(\%)=[($ Initial amount of paclitaxel - amount of free paclitaxel $) /($ Initial amount of paclitaxel) $] \times 100$

Author contributions: Concept - Y.B., H.A., O.B; Design - Y.B., H.A., O.B; Supervision - Y.B., O.B; Materials - Y.B., H.A., O.B; Data Collection and/or Processing - Y.B., H.A., O.B; Analysis and/or Interpretation - Y.B., H.A., O.B; Literature Search - Y.B., H.A., O.B; Writing - Y.B., O.B; Critical Reviews - Y.B., H.A., O.B.

Conflict of interest statement: The authors declared no conflict of interest.

\section{REFERENCES}

[1] Jordan MA, Wilson L. Microtubules as a target for anticancer drugs. Nat Rev Cancer. 2004; 4: 253-265. [CrossRef]

[2] Ramalingam SS, Owonikoko TK, Khuri FR. Lung cancer: New biological insights and recent therapeutic advances. CA Cancer J Clin. 2011; 61(2): 91-112. [CrossRef]

[3] Jemal A, Bray F, Center MM, Ferla J, Ward E, Forman D. Global cancer statistics. CA Cancer J Clin. 2011; 61(2): 69_ 90. [CrossRef]

[4] Sivarajakumar R, Mallukaraj D, Kadavakollu M, Neelakandan N, Chandran S, Bhojaraj S, Reddy Karri VVS. Nanoparticles for the treatment of lung cancers. J Young Pharm. 2018; 10(3): 276-281. [CrossRef]

[5] Horwitz SB. Taxol (paclitaxel): Mechanisms of action. Ann Oncol: Off J Eur Soc Med Onc. 1994; 5, S3-6.

[6] Gelderblom H, Verweij J, Nooter K, Sparreboom A. Cremophor EL: The drawbacks and advantages of vehicle selection for drug formulation. Eur J Cancer. 2001; 37: 1590-1598. [CrossRef]

[7] van Tellingen O, Huizing MT, Panday VR, Schellens JH, Nooijen WJ, Beijnen JH. Cremophor EL causes (pseudo-) non-linear pharmacokinetics of paclitaxel in patients. Br J Cancer. 1999; 81: 330-335. [CrossRef]

[8] Lubejko BG, Sartorius SE. Nursing considerations in paclitaxel (Taxol®) administration. Sem Onc. 1993; 20: 26-30. [CrossRef]

[9] Stinchcombe TE. Nanoparticle albumin-bound paclitaxel: A novel Cremphor-EL-free formulation of paclitaxel. Nanomed. 2007; 2: 415-423. [CrossRef]

[10] Lu J, Huang Y, Zhao W, Marquez RT, Meng X, Li J, Gao X, Venkataramanan R, Wang Z, Li S. PEG-derivatized embelin as a nanomicellar carrier for delivery of paclitaxel to breast and prostate cancers. Biomat. 2013; 34: 1591-1600. [CrossRef]

[11] Surapaneni MS, Das SK, Das NG. Designing paclitaxel drug delivery systems aimed at improved patient outcomes: current status and challenges. ISRN Pharmacol. 2012: 623139. [CrossRef]

[12] Koudelka S, Turánek J. Liposomal paclitaxel formulations. J Contr Rel. 2012; 163(3): 322-34. [CrossRef]

[13] McCormack B, Gregoriadis G. Entrapment of cyclodextrin-drug complexes into liposomes: potential advantages in drug delivery. J Drug Target. 1994; 2: 449-454. [CrossRef]

[14] Bernsdorff C, Reszka R, Winter R. Interaction of the anticancer agent Taxol ${ }^{\mathrm{TM}}$ (paclitaxel) with phospholipid bilayers. J Biomed Mat Res. 1999; 46: 141-149.

[15] Sampedro F, Partika J, Santalo P, Molins-Pujol AM, Bonal J, Perez-Soler R. Liposomes as carriers of different new lipophilic antitumour drugs: A preliminary report. J Microencaps. 1994; 11: 309-318. [CrossRef]

[16] Sharma A, Straubinger RM. Novel taxol formulations: preparation and characterization of taxol-containing liposomes. Pharm Res. 1994; 11: 889-896.

[17] Torchilin V. Multifunctional and stimuli-sensitive pharmaceutical nanocarriers. Eur J Pharm Biopharm. 2009; 7: 431444. [CrossRef] 
[18] Ruenraroengsak P, Cook JM, Florence AT. Nanosystem drug targeting: Facing up to complex realities. J Contr Rel. 2010; 141: 265-76. [CrossRef]

[19] Sultana S, Khan MR, Kumar M, Kumar S, Ali M. Nanoparticles-mediated drug delivery approaches for cancer targeting: a review. J Drug Target. 2013; 21: 107-25. [CrossRef]

[20] Li L, Ahmed B, Mehta K, Kurzrock R. Liposomal curcumin with and without oxaliplatin: Effects on cell growth, apoptosis, and angiogenesis in colorectal cancer. Mol Cancer Ther. 2007; 6(4): 1276-1282. [CrossRef]

[21] Lin CC, Lin HY, Chen HC, Yu MW, Lee MH. Stability and characterisation of phospholipid-based curcuminencapsulated microemulsions. Food Chem. 2009; 116(4): 923-928. [CrossRef]

[22] Yu HL, Huang QR. Enhanced in vitro anti-cancer activity of curcumin encapsulated in hydrophobically modified starch. Food Chem. 2010; 119(2): 669-674. [CrossRef]

[23] Jin C, Bai L, Wu H, Liu J, Guo G, Chen J. Paclitaxel-loaded poly (D,L-lactide-co-glycolide) nanoparticles for radiotherapy in hypoxic human tumor cells in vitro. Cancer Biol Ther. 2008; 7: 911-916. [CrossRef]

[24] Danhier F, Lecouturier N, Vroman B, Jérôme C, Marchand-Brynaert J, Feron O, Preat V. Paclitaxel-loaded PEGylated PLGA-based nanoparticles: In vitro and in vivo evaluation. J Contr Rel. 2009; 133: 11-17. [CrossRef]

[25] Arica-Yegin B, Benoît JP, Lamprecht A. Paclitaxel-loaded lipid nanoparticles prepared by solvent injection or ultrasound emulsification. Drug Dev Ind Pharm. 2006; 32: 1089-1094. [CrossRef]

[26] Jores K, Mehnert W, Drechsler M, Bunjes H, Johann C, Maeder K. Investigations on the structure of solid lipid nanoparticles (SLN) and oil-loaded solid lipid nanoparticles by photon correlation spectroscopy, field-flow fractionation and transmission electron microscopy. J Contr Rel. 2004; 95: 217-227. [CrossRef]

[27] Ganta S, Amiji M. Coadministration of Paclitaxel and curcumin in nanoemulsion formulations to overcome multidrug resistance in tumor cells. Mol Pharm. 2009; 6: 928-939. [CrossRef]

[28] Wang Y, Lu ZX, Lv FX, Bie XM. Study on microencapsulation of curcumin pigments by spray drying. Eur Food Res Tech. 2009; 229(3): 391-396. [CrossRef]

[29] Shaikh J, Ankola DD, Beniwal V, Singh D, Ravi Kumar MNV. Nanoparticle encapsulation improves oral bioavailability ofcurcumin by at least 9-times when compared to curcuminadministered with piperine as absorption enhancer. Eur J Pharm Sci. 2009; 37: 223-30. [CrossRef]

[30] Mukerjee A, Vishwanatha JK. Formulation, characterization and evaluation of curcumin-loaded PLGA nanospheres for cancer therapy. Anticancer Res. 2009; 29(10): 3867-3875.

[31] Prajakta D, Ratnesh J, Chandan K, Suresh S, Grace S, Meera V, Vandana P. Curcumin loaded ph-sensitive nanoparticles for the treatment of colon cancer. J Biomed Nanotech. 2009; 5: 445-455.

[32] Gomez-Estaca J, Balaguer MP, Gavara R, Hernandez-Munoz P. Formation of zein nanoparticles by electrohydrodynamic atomization: Effect of the main processing variables and suitability for encapsulating the food coloring and active ingredient curcumin. Food Hydrocolloids. 2012; 28: 82-91. [CrossRef]

[33] Jaworek A. Electrostatic micro- and nanoencapsulation and electroemulsification: A brief review. J Microencaps. 2008; 25 (7): 443-468. [CrossRef]

[34] Zhang L, Huang J, Si T, Xu RX. Coaxial electrospray of microparticles and nanoparticles for biomedical applications. Expert Rev Med Devices. 2012; 9(6): 595-612. [CrossRef]

[35] Cao L, Luo J, Tu K, Wang LQ, Jiang H. Generation of nano-sized core-shell particles using a coaxialtri-capillary electrospray-template removal method. Coll Surf B: Biointerfaces. 2014; 115: 212-218. [CrossRef]

[36] Yun KM, Suryamas AB, Hirakawa C, Iskandar F, Okuyama K. A new physicalroute to produce monodispersed microsphere nanoparticle-polymer composites. Langmuir. 2009; 25: 11038-11042. [CrossRef]

[37] Ding L, Lee T, Wang CH. Fabrication of monodispersed taxol-loaded particles using electrohydrodynamic atomization. J Contr Rel. 2005; 102: 395-413. [CrossRef]

[38] Kim W, Kim SS. Synthesis of biodegradable triple-layered capsules using atriaxial electrospray method. Polymer. 2011; 52: 3325-3336. [CrossRef]

[39] Valo H, Peltonen L, Vehvilainen S, Karjalainen M, Kostiainen R, Laaksonen T, Hirvonen J. Electrospray encapsulation of hydrophilic and hydrophobic drugsin poly (l-lactic acid) nanoparticles. Small. 2009; 5: 1791-1798. [CrossRef]

[40] Zhang S, Kawakami K, Yamamoto M, Masaoka Y, Kataoka M, Yamashita S, Sakuma S. Coaxial electrospray formulations for improving oral absorption of apoorly water-soluble drug. Mol Pharm. 2011; 8: 807-813. [CrossRef] 
[41] Chang MW, Stride E, Edirisinghe M. A new method for the preparation of monoporous hollow microspheres. Langmuir. 2010; 26: 5115-5121. [CrossRef]

[42] Zhang S, Kawakami K. One-step preparation of chitosan solid nanoparticlesby electrospray deposition. Int J Pharm. 2010; 397: 211-217. [CrossRef]

[43] Kose MD, Bayraktar O. Encapsulation of lycopene using electrospraying method. Biointerface Res Appl Chem. 2016; 6 (4): 1417-142.

[44] Baspinar Y, Üstündaş M, Bayraktar O, Sezgin C. Response surface methodology for extraction of curcumin from turmeric and piperine from black pepper. Celal Bayar University J Sci. 2017; 13 (3): 747-754. [CrossRef]

[45] Shukla R, Cheryan M. Zein: the industrial protein from corn. Ind Crops Prod. 2001; 13(3): 171-192. [CrossRef]

[46] Patel A, Hu YC, Tiwari JK, Velikov KP. Synthesis and characterisation of zein-curcumin colloidal particles. Soft Matter. 2010; 6(24): 6192-6199. [CrossRef]

[47] Liu XM, Sun QS, Wang HJ, Zhang L, Wang JY. Microspheres of corn protein, zein, for an ivermectin drug delivery system. Biomaterials. 2005; 26(1): 109-115. [CrossRef]

[48] Zhong QX, Jin MF. Nanoscalar structures of spray-dried zein microcapsules and in vitro release kinetics of the encapsulated lysozyme as affected by formulations. J Agricul Food Chem. 2009; 57(9): 3886-3894. [CrossRef]

[49] Nagpal K, Singh SK, Mishra DN. Chitosan nanoparticles: a promising system in novel drug delivery. Chem Pharm Bull. 2010; 58: 1423-30. [CrossRef]

[50] Helander IM, Nurmiaho-Lassila EL, Ahvenainen R, Rhoades J, Roller S. Chitosan disrupts the barrier properties of the outer membrane of Gram-negative bacteria. Int J Food Microbiol. 2001; 71(2-3): 235-244. [CrossRef]

[51] Gordon S, Saupe A, McBurney W, Rades T, Hook S. Comparison of chitosan nanoparticles and chitosan hydrogels for vaccine delivery. J Pharm Pharmacol. 2008; 60: 1591-600. [CrossRef]

[52] Luo Y, Wang Q. Recent development of chitosan-based polyelectrolytecomplexes with natural polysaccharides for drug delivery. Int J Biol Macromol. 2014; 64: 353-367. [CrossRef]

[53] Rojanasakul Y, Wang LY, Bhat M, Glover DD, Malanga CJ, Ma JKH. The transport barrier of epithelia: A comparative study on membrane permeability and charge selectivity in the rabbit. Pharm Res. 1992; 9: 1029-1034.

[54] Thanou M, Verhoef JC, Junginger HE. Chitosan and its derivatives as intestinal absorption enhancers. Adv Drug Del Rev. 2001; 50: 91-101. [CrossRef]

[55] Hartman RPA, Brunner DJ, Camelot DMA, Marijnissen JCM, Scarlett B. Electrohydrodynamic atomization in the cone-jet mode physical modeling of the liquid cone and jet. J Aerosol Sci. 1999; 30(7): 823-849. [CrossRef]

[56] Ding L, Lee T, Wang CH. Fabrication of monodispersed taxol-loaded particles using electrohydrodynamic atomization. J Contr Rel. 2005; 102: 395-413. [CrossRef]

[57] Xie JW, Marijnissen JCM, Wang CH. Microparticles developed by electrohydrodynamic atomization for the local delivery of anticancer drug to treat c6 glioma in vitro. Biomat. 2006; 27: 3321-3332. [CrossRef]

[58] Xie J, Ng WJ, Lee LY, Wang C-H. Encapsulation of protein drugs in biodegradable microparticles by co-axial electrospray. J Coll Interf Sci. 2008; 317: 469-476. [CrossRef]

[59] Furman C, Carpentier R, Barczyk A, Chavatte P, Betbeder D, Lipka E. Development and validation of a reversedphase UPLC method for the quantification of paclitaxel in different PLGA nanocarriers. Electrophoresis. 2017; 38: 2536-2541. [CrossRef]

[60] Erel Akbaba G, Akbaba H, Kantarc1 AG. Development and in vitro evaluation of positive-charged solid lipid nanoparticles as nucleic acid delivery system in glioblastoma treatment. J Res Pharm. 2018; 22(2): 299-306. [CrossRef]

[61] Baspinar Y, Üstündaş M, Bayraktar O, Sezgin C. Curcumin and piperine loaded zein-chitosan nanoparticles: Development and in-vitro characterisation. Saudi Pharm J. 2018; 26: 323-334. [CrossRef] 